\title{
TIPS-Naphthalene for Efficient Visible-to-UV Photon Upconversion under Sunlight and Room Light
}

\author{
Naoyuki Harada, ${ }^{\dagger}$ Yoichi Sasaki, ${ }^{\dagger}$ Masanori Hosoyamada, ${ }^{\dagger}$ Nobuo Kimizuka ${ }^{* \dagger}$ and Nobuhiro Yanai ${ }^{*}, \dagger, *$ \\ ${ }^{\dagger}$ Department of Chemistry and Biochemistry, Graduate School of Engineering, Center for Molecular Systems (CMS), Kyu- \\ shu University, 744 Moto-oka, Nishi-ku, Fukuoka 819-0395, Japan. \\ ${ }^{\ddagger}$ PRESTO, JST, Honcho 4-1-8, Kawaguchi, Saitama 332-0012, Japan. \\ ABSTRACT: Until now, the efficiency of triplet-triplet annihilation-based photon upconversion (TTA-UC) from visible to ultravi- \\ olet (UV) light has been limited to ca. $10 \%$ due to the absence of high-performance acceptors (emitters). Here, we present the first \\ example of visible-to-UV TTA-UC internal efficiency $\eta_{\text {UC }}$ beyond $20 \%$ by developing a novel UV emitter, 1,4-bis((triisopropylsi- \\ lyl)ethynyl)naphthalene (TIPS-Nph), and sensitizing its triplet by a donor $\operatorname{Ir}(\mathrm{C} 6)_{2}(\mathrm{acac})$ with strong visible absorption and weak UV \\ absorption. Under optimized conditions, $97 \%$ of the excitation light is absorbed, the threshold excitation intensity $\left(I_{\text {th }}=1.1 \mathrm{~mW} \mathrm{~cm}^{-2}\right)$ \\ is lower than the solar irradiance $\left(1.4 \mathrm{~mW} \mathrm{~cm}^{-2}\right.$ for $\left.445 \pm 5 \mathrm{~nm}\right)$, and significantly, the highest external UC efficiency $\eta \mathrm{UC}$,ext of $17.4 \%$ \\ for vis-to-UV TTA-UC is achieved. Upconverted UV emission can also be obtained with weak light sources such as an AM 1.5 solar \\ simulator and room LEDs, paving the way for a variety of solar and indoor applications.
}

Triplet-triplet annihilation-based photon upconversion (TTA-UC) has attracted much interest because of its potential to efficiently convert lower-energy photons to higher-energy photons at a weak excitation intensity. ${ }^{1-19}$ TTA-UC occurs in multi-chromophore systems wherein the excited triplet energy of a donor (sensitizer) is transferred to an acceptor (emitter), and sensitized acceptor triplets annihilate to show an upconverted emission (Figure 1a).

While the conversion of visible light (vis, $\lambda>400 \mathrm{~nm}$ ) to ultraviolet light (UV, $\lambda<400 \mathrm{~nm}$ ) is crucial for artificial photosynthesis and photocatalytic environmental cleanup, the efficiency of vis-to-UV TTA-UC ( $\left.\eta_{\mathrm{UC}}\right)$ at solar irradiance has been limited. ${ }^{20-30}$ Relatively high vis-to-UV $\eta_{\text {UC }}$ values of $5.2 \%$ and $10.2 \%$ have been observed by using semiconductor nanocrystals as donor and 2,5-diphenyloxazole (PPO) as acceptor. ${ }^{31,32}$ However, their threshold excitation intensities $\left(I_{\text {th }}\right)$, at which half of the maximum $\eta_{\mathrm{UC}}$ is obtained, were much higher (ca. 2 $\mathrm{W} \mathrm{cm}{ }^{-2}$ ) than solar irradiance (a few $\mathrm{mW} \mathrm{cm}^{-2}$ ). It was difficult to lower the $I_{\text {th }}$ value without dropping the $\eta_{\mathrm{UC}}$ since the broad absorption of semiconductor nanocrystals in the UV region inevitably induces the re-absorption and back energy transfer at higher donor concentrations.

Here, we show the first example of vis-to-UV TTA-UC efficiency $\eta_{\mathrm{UC}}$ over $20 \%$ by developing a novel acceptor $1,4-$ bis((triisopropylsilyl)ethynyl)naphthalene (TIPS-Nph, Figure 1a) with a high singlet generation probability $f$ by TTA and combining it with a molecular donor we developed earlier, $\operatorname{Ir}(\mathrm{C} 6)_{2}(\mathrm{acac})(\mathrm{C} 6=$ coumarin 6, acac $=$ acetylacetone $){ }^{22}$ The highest $\eta_{\mathrm{UC}}$ value is certified by absolute quantum yield measurements. ${ }^{33,34}$ Thanks to the strong visible absorption over $80,000 \mathrm{M}^{-1} \mathrm{~cm}^{-1}$ and weak UV absorption of $\operatorname{Ir}(\mathrm{C} 6)_{2}(\mathrm{acac}),{ }^{22,35,36}$ the $I_{\text {th }}$ value reaches a sub-solar irradiance without dropping the $\eta_{\mathrm{UC}}$, resulting in the highest external UC efficiency $\eta \mathrm{UC}$,ext of $17.4 \%$ for vis-to-UV TTA-UC. Remarkably, an upconverted UV emission was also observed under an AM 1.5 solar simulator and desk LED light (Figure 1b-e).

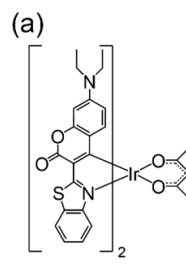
$\operatorname{Ir}(\mathrm{C} 6)_{2}($ acac $)$

(b)

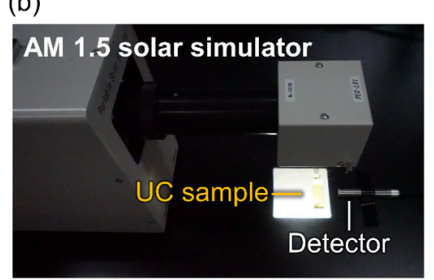

(d)

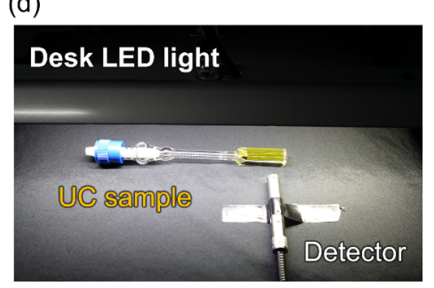

(e)

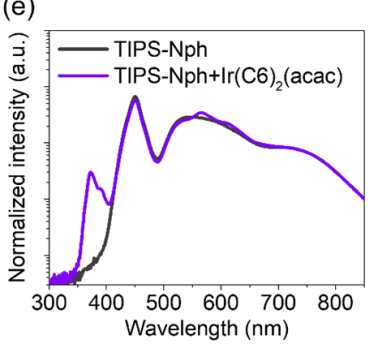

Figure 1. (a) Energy diagram of vis-to-UV TTA-UC using a donor $\operatorname{Ir}(\mathrm{C} 6)_{2}(\mathrm{acac})$ and a novel acceptor TIPS-Nph. Pictures and spectra (normalized at $850 \mathrm{~nm}$ ) of TIPS-Nph $(10 \mathrm{mM})$ with (purple)/without (gray) $\operatorname{Ir}(\mathrm{C} 6)_{2}$ (acac) $(100 \mu \mathrm{M})$ in deaerated THF under $(\mathrm{b}, \mathrm{c})$ an AM1.5 solar simulator (450 nm long-pass filter is included) and (d, e) a desk LED light without using any further lens and filter. 
Considering that TIPS-tetracene/anthracene are well-studied compounds, ${ }^{16,37,38}$ it is a bit surprising that TIPS-Nph is a new compound. We synthesized TIPS-Nph and fully characterized it (see Supporting Information (SI)). A THF solution of TIPS$\mathrm{Nph}(100 \mu \mathrm{M})$ showed a $0-0$ absorption peak at $350 \mathrm{~nm}(3.54$ $\mathrm{eV}$ ) and a vibronic fluorescence spectrum in the UV region (Figure S4) with an absolute fluorescence quantum yield $\Phi_{\mathrm{FL}}$ of $74 \%$ ( $\lambda_{\text {ex }}=320 \mathrm{~nm}$ ). $\operatorname{Ir}(\mathrm{C} 6)_{2}$ (acac) shows two absorption bands at 445 and $474 \mathrm{~nm}$ and phosphorescence at $567 \mathrm{~nm}(2.19 \mathrm{eV})$ (Figure S4). As we discussed previously, the sharp and intense ligand-centered $\pi-\pi^{*}$ absorption bands of $\operatorname{Ir}(\mathrm{C} 6)_{2}$ (acac) are useful to avoid the quenching of upconverted UV emission. ${ }^{22}$

Under excitation by a $445 \mathrm{~nm}$ laser, an upconverted emission in the UV region was observed in a deaerated THF solution of $\operatorname{Ir}(\mathrm{C} 6)_{2}(\mathrm{acac})$ and TIPS-Nph (Figure $2 \mathrm{a},\left[\operatorname{Ir}(\mathrm{C} 6)_{2}(\mathrm{acac})\right]=100$ $\mu \mathrm{M},[$ TIPS-Nph] $=10 \mathrm{mM})$. The ms-scale delayed emission supports the triplet-mediated mechanism (Figure S5). The TTA-UC efficiency $\eta_{\mathrm{UC}}$ is standardized to a theoretical maximum of $100 \% .{ }^{39}$ The $\eta_{\mathrm{UC}}$ value of $\operatorname{Ir}(\mathrm{C} 6)_{2}$ (acac) and TIPS-Nph was determined as $20.5 \%$ by the relative method (Figure $2 b$, see SI for details). The reliability of the highest $\eta_{U C}$ was confirmed by a similar value of $21.4 \%$ at $17.2 \mathrm{~W} \mathrm{~cm}^{-2}$ obtained by the absolute method in the integrating sphere (see SI for details) ${ }^{33,34}$ This $\eta_{\text {UC }}$ is the highest value for vis-to-UV TTA-UC ever reported and twice higher than the previous record $(10.2 \%) .{ }^{32}$ On the other hand when the previous best acceptor $\mathrm{PPO}^{21,27,30-32}$ was combined with $\operatorname{Ir}(\mathrm{C} 6)_{2}$ (acac) in THF, no upconverted emission was observed (Figure S6).

The triplet energy transfer (TET) efficiency $\Phi_{\text {TET }}$ was estimated by measuring the sensitizer phosphorescence quantum yield (see SI for details). The efficiency of $\operatorname{Ir}(\mathrm{C} 6)_{2}$ (acac)-toTIPS-Nph and $\operatorname{Ir}(\mathrm{C} 6)_{2}$ (acac)-to-PPO TET were $97 \%$ and almost $0 \%$, respectively. The absence of TET is the reason for no TTA$\mathrm{UC}$ emission from the $\operatorname{Ir}(\mathrm{C} 6)_{2}(\mathrm{acac})$ and PPO solution.

To explain the difference of $\Phi_{\text {TET values between TIPS-Nph }}$ and PPO, we carried out density functional theory (DFT) calculations of TIPS-Nph and PPO. The estimated $\mathrm{S}_{1}$ energy level of TIPS-Nph was $3.44 \mathrm{eV}$, which agrees well with the observed absorption peak at $3.54 \mathrm{eV}$. The estimated $\mathrm{T}_{1}$ energy levels of TIPS-Nph $(2.10 \mathrm{eV})$ was lower than that of PPO $(2.51 \mathrm{eV})$, which would be responsible for the observed differences in the TET efficiency and the occurrence of TTA-UC. Therefore, it was necessary to use the donor with large UV absorption for sensitizing PPO triplet, which has limited the $\eta_{\mathrm{UC}}$ and $I_{\text {th }}$ values.

The UC efficiency $\eta_{\mathrm{UC}}$ is described by the following expression, ${ }^{6}$

$$
\eta_{\mathrm{UC}}=f \Phi_{\mathrm{ISC}} \Phi_{\mathrm{TET}} \Phi_{\mathrm{TTA}} \Phi_{\mathrm{FL}}
$$

where $\Phi_{\text {ISC }}$ and $\Phi_{\text {TTA }}$ represent the quantum yields of donor ISC and TTA. In the current system, the $\Phi_{\mathrm{ISC}}$ and $\Phi_{\mathrm{TTA}}$ values are assumed to be close to 1 since there is no donor fluorescence and the excitation intensity is in the linear regime as shown later. By increasing the acceptor concentration from $100 \mu \mathrm{M}$ to 10 $\mathrm{mM}$, the $\Phi_{\mathrm{FL}}$ value decreased from $74 \%$ to $66 \%$. This decrease is due to the inner filter effect, as confirmed by the disappearance of the short-wavelength fluorescence component at $10 \mathrm{mM}$ (Figure S7). From these parameters, the relatively high $f$ value of $32 \%$ was estimated for TIPS-Nph, and this is the main reason for the highest vis-to-UV TTA-UC efficiency. The high $f$ value may be associated with the reduction of nonradiative loss in the TTA process by the rigid bonding of the ethynyl group, as recently suggested by Rao and coworkers. ${ }^{38}$ Ethynyl naphthalene can be the promising structural unit for vis-to-UV TTA-UC, and we expect that the TTA-UC efficiency can be further improved by increasing the fluorescence quantum yield through the optimization of the acceptor structure.

(a)
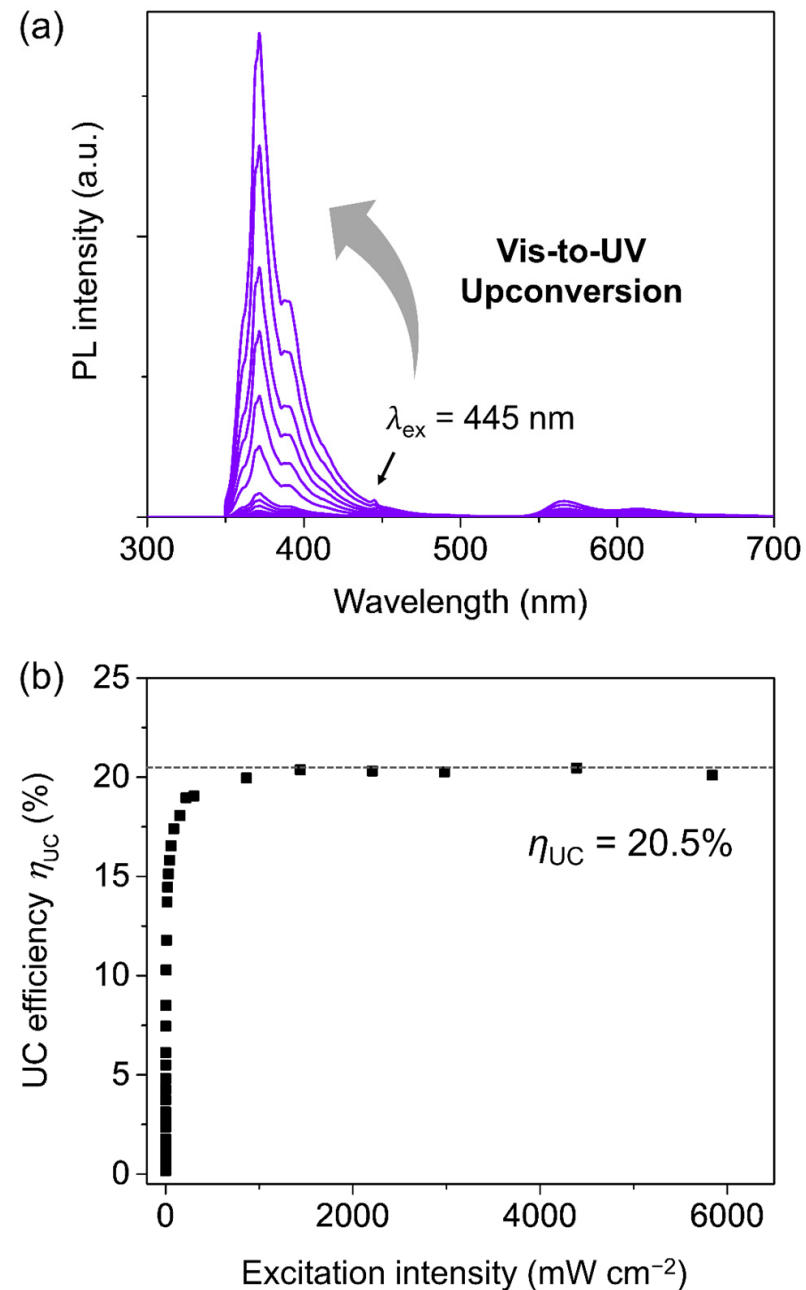

Figure 2. (a) Photoluminescence (PL) spectra of $\operatorname{Ir}(\mathrm{C} 6)_{2}$ (acac) and TIPS-Nph in deaerated THF $\left(\left[\operatorname{Ir}(\mathrm{C} 6)_{2}(\mathrm{acac})\right]=100 \mu \mathrm{M}\right.$, [TIPS$\mathrm{Nph}]=10 \mathrm{mM}$ ) at various excitation intensities from $0.030 \mathrm{~mW}$ $\mathrm{cm}^{-2}$ to $5.8 \mathrm{~W} \mathrm{~cm}^{-2}$ ( $\lambda_{\mathrm{ex}}=445 \mathrm{~nm}$, no filter). (b) UC efficiency $\eta_{\mathrm{UC}}$ of $100 \mu \mathrm{M} \operatorname{Ir}(\mathrm{C} 6)_{2}$ (acac) and $10 \mathrm{mM}$ TIPS-Nph in deaerated THF at various excitation intensities of the $445 \mathrm{~nm}$ laser.

Besides the high $\eta_{\mathrm{UC}}$, the threshold excitation intensity $I_{\text {th }}$ is the key parameter to characterize TTA-UC. In the typical TTAUC systems, the UC emission intensity shows a quadratic and a linear dependence on the excitation intensity at low- and highintensity regimes, respectively. ${ }^{40-42}$ The intersection of the two fitting lines provides $I_{\mathrm{th}}$. The log-log plot of UC emission intensity of $100 \mu \mathrm{M} \operatorname{Ir}(\mathrm{C} 6)_{2}$ (acac) and $10 \mathrm{mM}$ TIPS-Nph against the excitation intensity showed a transition of slope from ca. 2.0 to 1.0 , giving a $I_{\text {th }}$ value of $2.3 \mathrm{~mW} \mathrm{~cm}^{-2}$ (Figure 3a). To further reduce the $I_{\text {th }}$ value, we increased the donor concentration from $100 \mu \mathrm{M}$ to $300 \mu \mathrm{M}$. Remarkably, the obtained $I_{\text {th }}$ of $1.1 \mathrm{~mW}$ $\mathrm{cm}^{-2}$ with $300 \mu \mathrm{M}$ of the donor is lower than the solar irradiance of $1.4 \mathrm{~mW} \mathrm{~cm}^{-2}$ for $445 \pm 5 \mathrm{~nm}$ (Figure $3 \mathrm{a}$ ).

While the common "internal" UC efficiency $\eta_{\text {UC }}$ gives an understanding of the basic UC properties, it is important to achieve 
a high "external" UC efficiency $\eta \mathrm{UC}$,ext for real-world applications. It is defined as

$$
\eta_{\mathrm{UC}, \mathrm{ext}}=\eta_{\mathrm{UC}} \times\left(1-10^{-A}\right)
$$

where $A$ represents the absorbance at the excitation wavelength $(445 \mathrm{~nm})$. Figure $3 \mathrm{~b}$ shows the excitation dependence of $\eta_{\mathrm{UC} \text {,ext }}$ for TIPS-Nph $(10 \mathrm{mM})$ with different concentrations of $\operatorname{Ir}(\mathrm{C} 6)_{2}(\mathrm{acac})(100$ and $300 \mu \mathrm{M})$. The highest $\eta_{\mathrm{UC} \text {,ext }}$ of $17.4 \%$ as vis-to-UV TTA-UC was achieved with $300 \mu \mathrm{M}$ of the donor. Remarkably, even at the solar irradiance of $1.4 \mathrm{~mW} \mathrm{~cm}^{-2}$, this sample shows a high $\eta_{\mathrm{UC} \text {,ext }}$ of about $6 \%$.

(a)

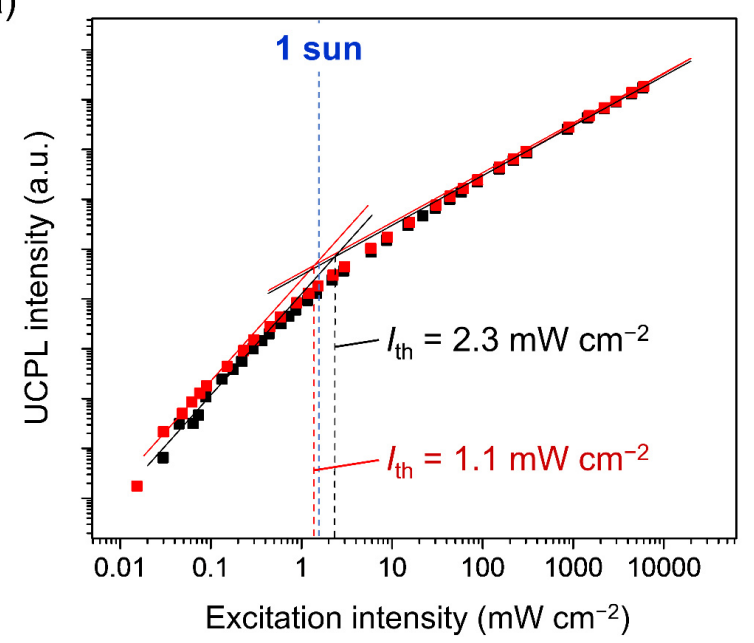

(b)

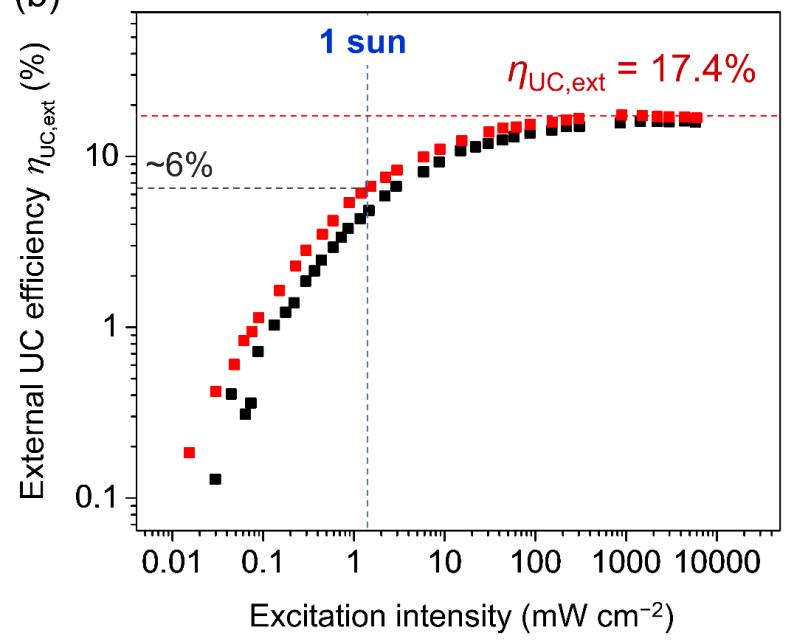

Figure 3. Excitation intensity dependence of (a) UC emission intensity and (b) external UC efficiency $\eta \mathrm{UC}$,ext of $\operatorname{Ir}(\mathrm{C} 6)_{2}(\mathrm{acac})(100$ $\mu \mathrm{M}$ (black), $300 \mu \mathrm{M}$ (red)) and TIPS-Nph $(10 \mathrm{mM})$ in deaerated THF $\left(\lambda_{\mathrm{ex}}=445 \mathrm{~nm}\right)$. Blue line indicates the intensity of sunlight $\left(1.4 \mathrm{~mW} \mathrm{~cm}^{-2}\right.$ for $\left.445 \pm 5 \mathrm{~nm}\right)$.

It's not uncommon for only high internal TTA-UC efficiency $\eta$ Uc to be reported by employing a low donor concentration (low absorbance), since the high donor absorbance leads to the undesirable re-absorption and back energy transfer. On the other hand, in the current system, the weak donor absorption at the UV region allows us to realize the high visible absorbance and the high internal UC efficiency $\eta_{\mathrm{UC}}$ at the same time, resulting in the high external UC efficiency $\eta \mathrm{UC}$,ext. The $300 \mu \mathrm{M}$ donor absorbs $97 \%$ of $445 \mathrm{~nm}$ light $(A=1.55$, path length $=1 \mathrm{~mm})$. Significantly, the internal UC efficiency $\eta$ UC was maintained as high as $18.0 \%$ even at such high donor concentration (Figure S8). The acceptor-to-donor back singlet/triplet energy transfers are suppressed thanks to the small UV absorption of donor and the lower $T_{1}$ energy level of the acceptor than the donor, which was supported by similar acceptor fluorescence lifetimes with/without the donor (Figure S9) and similar acceptor triplet lifetimes at the different donor concentrations (Figure S5).

As a simple demonstration, we placed the deaerated THF solution of $\operatorname{Ir}(\mathrm{C} 6)_{2}(\mathrm{acac})$ and TIPS-Nph under the AM 1.5 solar simulator (Figure 1b). A $450 \mathrm{~nm}$ short-pass filter was introduced into the solar simulator to avoid the direct excitation of the acceptor. At 1 sun, without any focusing of the excitation light, an upconverted UV emission was observed from the mixed solution of $\operatorname{Ir}(\mathrm{C} 6)_{2}(\mathrm{acac})$ and TIPS-Nph (Figure 1c). The fact that no upconverted emission was observed in the absence of the donor confirms the sensitized TTA-UC. A nearly 100\% quantum yield of photocatalytic water splitting has been reported, but the absorption of the photocatalysts was limited to the UV range..$^{43}$ It is anticipated to add the visible light sensitivity to these ultimate photocatalysts by the vis-to-UV TTA-UC.

Indoor applications of vis-to-UV TTA-UC are challenging since the intensity of common room light is even weaker than sunlight. We tested our TTA-UC system by using the desk LED light whose intensity for the blue portion $(\lambda<500 \mathrm{~nm})$ is ca. 0.7 $\mathrm{mW} \mathrm{cm}{ }^{-2}$ at a separation of about $7 \mathrm{~cm}$ from the LED surface (Figure 1d). Even at such a low excitation intensity, the deaerated THF solution of $\operatorname{Ir}(\mathrm{C} 6)_{2}(\mathrm{acac})$ and TIPS-Nph clearly showed an upconverted UV emission, while the TIPS-Nph solution without the donor did not show any UV emission (Figure 1e). Moreover, the upconverted emission was observed at different distances from the desk LED light from $5 \mathrm{~cm}$ to $50 \mathrm{~cm}$, where the LED light intensity $(\lambda<500 \mathrm{~nm})$ varied from 0.88 $\mathrm{mW} \mathrm{cm}{ }^{-2}$ to $0.065 \mathrm{~mW} \mathrm{~cm}^{-2}$ (Figure $\mathrm{S} 10$ ). By formulating the solid-state upconverters based on the current donor-acceptor dyes and combining them with photocatalysts, TTA-UC would contribute to improving the indoor environments.

In conclusion, we show the first example of vis-to-UV TTAUC efficiency $\eta_{\mathrm{UC}}$ beyond $20 \%$, which is two times higher than the previous record. The highest $\eta \mathrm{UC}$ value was certified by the absolute quantum yield measurements. This new record originates from the high $f$ value of the novel acceptor TIPS-Nph and the strong visible absorption and weak UV absorption of donor $\operatorname{Ir}(\mathrm{C} 6)_{2}(\mathrm{acac})$. This donor-acceptor pair gives the threshold excitation intensity $I_{\text {th }}$ as low as $1.1 \mathrm{~mW} \mathrm{~cm}^{-2}$, being lower than the solar irradiance. While it is usually challenging to achieve the high external UC efficiency $\eta_{\mathrm{UC} \text {,ext }}$ due to the severe quenching of UC emission at a high donor concentration, the favorable absorption feature of the donor and the lower triplet energy of acceptor than the donor realize the record external efficiency $\eta_{\mathrm{UC} \text {,ext }}$ of $17.4 \%$ for vis-to-UV TTA-UC. Even weak visible light within the sunlight and room LED light can be effectively converted to UV light, showing the promising potential of vis-toUV TTA-UC for various solar and indoor applications.

\section{ASSOCIATED CONTENT}

Supporting Information. The Supporting Information is available free of charge on the ACS Publication website at DOI: xx.xxxx/jacs.Xxxxxxx.

Experimental details, NMR spectra, UV-vis absorption spectra, photoluminescence spectra, decays and spectra of UC emission, excitation intensity dependence of UC efficiency, fluorescence decays. 


\section{AUTHOR INFORMATION}

\section{Corresponding Author}

*yanai@mail.cstm.kyushu-u.ac.jp

*n-kimi@mail.cstm.kyushu-u.ac.jp

Notes

The authors declare no competing financial interest.

\section{ACKNOWLEDGMENT}

This work was partly supported by JSPS KAKENHI (grant numbers JP20H02713, JP16H06513, JP18J21140), the Sumitomo Foundation, the Ogasawara Foundation, and the Innovation inspired by Nature Program of Sekisui Chemical Co. Ltd.

\section{REFERENCES}

(1) Baluschev, S.; Miteva, T.; Yakutkin, V.; Nelles, G.; Yasuda, A.; Wegner, G. Up-Conversion Fluorescence: Noncoherent Excitation by Sunlight. Phys. Rev. Lett. 2006, 97, 143903.

(2) Singh-Rachford, T. N.; Castellano, F. N. Photon upconversion based on sensitized triplet-triplet annihilation. Coord. Chem. Rev. 2010, 254, 2560-2573.

(3) Zhao, J.; Ji, S.; Guo, H. Triplet-triplet annihilation based upconversion: from triplet sensitizers and triplet acceptors to upconversion quantum yields. $R S C A d v$. 2011, 1, 937-950.

(4) Kim, J. H.; Kim, J. H. Encapsulated Triplet-Triplet Annihilation-Based Upconversion in the Aqueous Phase for Sub-BandGap Semiconductor Photocatalysis. J. Am. Chem. Soc. 2012, 134, 17478-17481.

(5) Simon, Y. C.; Weder, C. Low-power photon upconversion through triplet-triplet annihilation in polymers. J. Mater. Chem. 2012, 22, 20817-20830.

(6) Monguzzi, A.; Tubino, R.; Hoseinkhani, S.; Campione, M.; Meinardi, F. Low power, non-coherent sensitized photon up-conversion: modelling and perspectives. Phys. Chem. Chem. Phys. 2012, 14, 4322-4332.

(7) Gray, V.; Dzebo, D.; Abrahamsson, M.; Albinsson, B.; MothPoulsen, K. Triplet-triplet annihilation photon-upconversion: towards solar energy applications. Phys. Chem. Chem. Phys. 2014, 16, 10345-10352.

(8) Andernach, R.; Utzat, H.; Dimitrov, S. D.; McCulloch, I.; Heeney, M.; Durrant, J. R.; Bronstein, H. Synthesis and Exciton Dynamics of Triplet Sensitized Conjugated Polymers. J. Am. Chem. Soc. 2015, 137, 10383-10390.

(9) Wu, M.; Congreve, D. N.; Wilson, M. W. B.; Jean, J.; Geva, N.; Welborn, M.; Van Voorhis, T.; Bulović, V.; Bawendi, M. G.; Baldo, M. A. Solid-state infrared-to-visible upconversion sensitized by colloidal nanocrystals. Nat. Photon. 2016, 10, 31-34.

(10) Yanai, N.; Kimizuka, N. New Triplet Sensitization Routes for Photon Upconversion: Thermally Activated Delayed Fluorescence Molecules, Inorganic Nanocrystals, and Singlet-to-Triplet Absorption. Acc. Chem. Res. 2017, 50, 2487-2495.

(11) Hill, S. P.; Hanson, K. Harnessing Molecular Photon Upconversion in a Solar Cell at Sub-solar Irradiance: Role of the Redox Mediator. J. Am. Chem. Soc. 2017, 139, 10988-10991.

(12) Huang, Z.; Tang, M. L. Designing Transmitter Ligands That Mediate Energy Transfer between Semiconductor Nanocrystals and Molecules. J. Am. Chem. Soc. 2017, 139, 9412-9418.

(13) Sato, R.; Kitoh-Nishioka, H.; Kamada, K.; Mizokuro, T.; Kobayashi, K.; Shigeta, Y. Synergetic Effects of Triplet-Triplet Annihilation and Directional Triplet Exciton Migration in Organic Crystals for Photon Upconversion. J. Phys. Chem. Lett. 2018, 9, 6638-6643.

(14) Rowe, J. M.; Zhu, J.; Soderstrom, E. M.; Xu, W.; Yakovenko, A.; Morris, A. J. Sensitized photon upconversion in anthracenebased zirconium metal-organic frameworks. Chem. Commun. 2018, 54, 7798-7801.

(15) Yang, X.; Han, J.; Wang, Y.; Duan, P. Photon-upconverting chiral liquid crystal: significantly amplified upconverted circularly polarized luminescence. Chem. Sci. 2019, 10, 172-178.
(16) Imperiale, C. J.; Green, P. B.; Miller, E. G.; Damrauer, N. H.; Wilson, M. W. B. Triplet-Fusion Upconversion Using a Rigid Tetracene Homodimer. J. Phys. Chem. Lett. 2019, 10, 7463 7469.

(17) Ravetz, B. D.; Pun, A. B.; Churchill, E. M.; Congreve, D. N.; Rovis, T.; Campos, L. M. Photoredox catalysis using infrared light via triplet fusion upconversion. Nature 2019, 565, 343-346.

(18) Wieghold, S.; Bieber, A. S.; VanOrman, Z. A.; Daley, L.; Leger, M.; Correa-Baena, J. P.; Nienhaus, L. Triplet Sensitization by Lead Halide Perovskite Thin Films for Efficient Solid-State Photon Upconversion at Subsolar Fluxes. Matter 2019, 1, 705-719.

(19) Gholizadeh, E. M.; Prasad, S. K. K.; Teh, Z. L.; Ishwara, T.; Norman, S.; Petty, A. J.; Cole, J. H.; Cheong, S.; Tilley, R. D.; Anthony, J. E.; Huang, S.; Schmidt, T. W. Photochemical upconversion of near-infrared light from below the silicon bandgap. Nat. Photon. 2020, 14, 585-590.

(20) Zhao, W.; Castellano, F. N. Upconverted Emission from Pyrene and Di-tert-butylpyrene Using $\operatorname{Ir}(\mathrm{ppy})_{3}$ as Triplet Sensitizer. $J$. Phys. Chem. A 2006, 110, 11440-11445.

(21) Singh-Rachford, T. N.; Castellano, F. N. Low Power Visible-toUV Upconversion. J. Phys. Chem. A 2009, 113, 5912-5917.

(22) Duan, P.; Yanai, N.; Kimizuka, N. A bis-cyclometalated iridium complex as a benchmark sensitizer for efficient visible-to-UV photon upconversion. Chem. Commun. 2014, 50, 13111-13113.

(23) Peng, J.; Guo, X.; Jiang, X.; Zhao, D.; Ma, Y. Developing efficient heavy-atom-free photosensitizers applicable to TTA upconversion in polymer films. Chem. Sci. 2016, 7, 1233-1237.

(24) Jiang, X.; Guo, X.; Peng, J.; Zhao, D.; Ma, Y. Triplet-Triplet Annihilation Photon Upconversion in Polymer Thin Film: Sensitizer Design. ACS Appl. Mater. Interfaces 2016, 8, 1144111449.

(25) Yanai, N.; Kozue, M.; Amemori, S.; Kabe, R.; Adachi, C.; Kimizuka, N. Increased vis-to-UV upconversion performance by energy level matching between a TADF donor and high triplet energy acceptors. J. Mater. Chem. C 2016, 4, 6447-6451.

(26) Chen, Q.; Liu, Y.; Guo, X.; Peng, J.; Garakyaraghi, S.; Papa, C. M.; Castellano, F. N.; Zhao, D.; Ma, Y. Energy Transfer Dynamics in Triplet-Triplet Annihilation Upconversion Using a Bichromophoric Heavy-Atom-Free Sensitizer. J. Phys. Chem. A 2018, 122, 6673-6682.

(27) Okumura, K.; Yanai, N.; Kimizuka, N. Visible-to-UV Photon Upconversion Sensitized by Lead Halide Perovskite Nanocrystals. Chem. Lett. 2019, 48, 1347-1350.

(28) Pfund, B.; Steffen, D. M.; Schreier, M. R.; Bertrams, M. S.; Ye, C.; Börjesson, K.; Wenger, O. S.; Kerzig, C. UV Light Generation and Challenging Photoreactions Enabled by Upconversion in Water. J. Am. Chem. Soc. 2020, 142, 10468-10476.

(29) Kawashima, Y.; Kouno, H.; Orihashi, K.; Nishimura, K.; Yanai, N.; Kimizuka, N. Visible-to-UV photon upconversion in air-saturated water by multicomponent co-assembly. Mol. Syst. Des. Eng. 2020, 5, 792-796.

(30) Hisamitsu, S.; Miyano, J.; Okumura, K.; Hui, J. K. H.; Yanai, N.; Kimizuka, N. Visible-to-UV Photon Upconversion in Nanostructured Chromophoric Ionic Liquids. ChemistryOpen 2020, 9, 14 17.

(31) Gray, V.; Xia, P.; Huang, Z.; Moses, E.; Fast, A.; Fishman, D. A.; Vullev, V. I.; Abrahamsson, M.; Moth-Poulsen, K.; Tang, M. L. CdS/ZnS core-shell nanocrystal photosensitizers for visible to UV upconversion. Chem. Sci. 2017, 8, 5488-5496.

(32) He, S.; Luo, X.; Liu, X.; Li, Y.; Wu, K. Visible-to-Ultraviolet Upconversion Efficiency above 10\% Sensitized by QuantumConfined Perovskite Nanocrystals. J. Phys. Chem. Lett. 2019, 10, 5036-5040.

(33) de Mello, J. C.; Wittmann, H. F.; Friend, R. H. An improved experimental determination of external photoluminescence quantum efficiency. Adv. Mater. 1997, 9, 230-232.

(34) Yanai, N.; Suzuki, K.; Ogawa, T.; Sasaki, Y.; Harada, N.; Kimizuka, N. Absolute Method to Certify Quantum Yields of Photon Upconversion via Triplet-Triplet Annihilation. J. Phys. Chem. A 2019, 123, 10197-10203. 
(35) Borisov, S. M.; Klimant, I. Ultrabright Oxygen Optodes Based on Cyclometalated Iridium(III) Coumarin Complexes. Anal. Chem. 2007, 79, 7501-7509.

(36) Lamansky, S.; Djurovich, P.; Murphy, D.; Abdel-Razzaq, F.; Lee, H. E.; Adachi, C.; Burrows, P. E.; Forrest, S. R.; Thompson, M. E. Highly Phosphorescent Bis-Cyclometalated Iridium Complexes: Synthesis, Photophysical Characterization, and Use in Organic Light Emitting Diodes. J. Am. Chem. Soc. 2001, 123, 4304-4312.

(37) Pun, A. B.; Sanders, S. N.; Sfeir, M. Y.; Campos, L. M.; Congreve, D. N. Annihilator dimers enhance triplet fusion upconversion. Chem. Sci. 2019, 10, 3969-3975.

(38) Nishimura, N.; Gray, V.; Allardice, J. R.; Zhang, Z.; Pershin, A.; Beljonne, D.; Rao, A. Photon Upconversion from Near-Infrared to Blue Light with TIPS-Anthracene as an Efficient Triplet-Triplet Annihilator. ACS Mater. Lett. 2019, 1, 660-664.

(39) Zhou, Y.; Castellano, F. N.; Schmidt, T. W.; Hanson, K. On the Quantum Yield of Photon Upconversion via Triplet-Triplet Annihilation. ACS Energy Lett. 2020, 5, 2322-2326.
(40) Monguzzi, A.; Mezyk, J.; Scotognella, F.; Tubino, R.; Meinardi, F. Upconversion-induced fluorescence in multicomponent systems: Steady-state excitation power threshold. Phys. Rev. B: Condens. Matter Mater. Phys. 2008, 78, 195112.

(41) Cheng, Y. Y.; Khoury, T.; Clady, R. G. C. R.; Tayebjee, M. J. Y.; Ekins-Daukes, N. J.; Crossley, M. J.; Schmidt, T. W. On the efficiency limit of triplet-triplet annihilation for photochemical upconversion. Phys. Chem. Chem. Phys. 2010, 12, 66-71.

(42) Haefele, A.; Blumhoff, J.; Khnayzer, R. S.; Castellano, F. N. Getting to the (Square) Root of the Problem: How to Make Noncoherent Pumped Upconversion Linear. J. Phys. Chem. Lett. 2012, 3, 299-303.

(43) Takata, T.; Jiang, J.; Sakata, Y.; Nakabayashi, M.; Shibata, N.; Nandal, V.; Seki, K.; Hisatomi, T.; Domen, K. Photocatalytic water splitting with a quantum efficiency of almost unity. Nature 2020, 581, 411-414. 


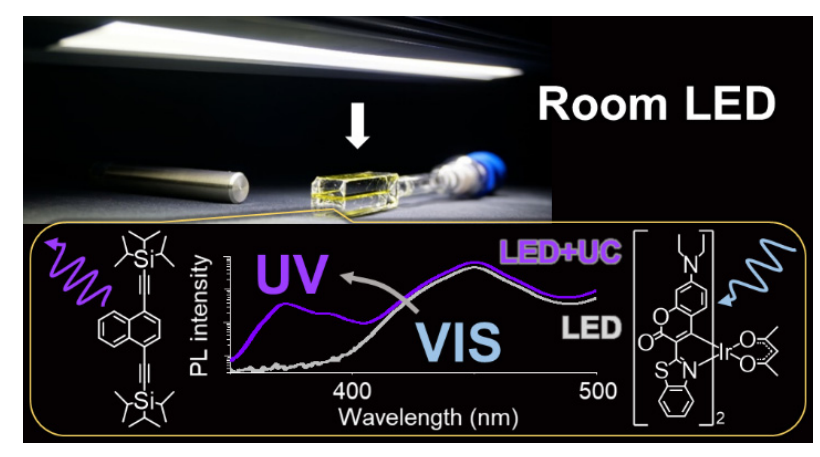

